\title{
Review
}

\section{Diagnosing diabetes mellitus - do we need new criteria?}

\author{
D.R . M cC ance ${ }^{1}$, R . L. H anson ${ }^{2}$, D.J. Pettitt ${ }^{2}$, P. H . B ennett ${ }^{2}$, D. R . H adden ${ }^{1}$, W. C. K nowler ${ }^{2}$ \\ ${ }^{1}$ Sir George E. Clark Metabolic Unit, Royal Victoria Hospital, Belfast, Northern Ireland, UK \\ ${ }^{2}$ Diabetes and Arthritis Epidemiology Section, National Institute of Diabetes and Digestive and Kidney Diseases, Phoenix, \\ Arizona, USA
}

Summary The current classification and diagnostic criteria for diabetes mellitus were introduced by the United States National Data Group in 1979 and endorsed by the World Health Organization in 1980, with modifications in 1985 and 1994. The criteria, chosen to reflect the risk of complications, were the synthesis of considerable thought and expertise and represented a consensus which, it was hoped, would prove helpful to all those involved with diabetes practising clinician, research scientist and epidemiologist alike. The inconvenience, variability and nonphysiological nature of the oral glucose tolerance test (OGTT) are well-recognised. In spite of these limitations the 2-h post-load plasma glucose has remained the standard against which all other tests have been evaluated. This article reviews the original justification for the OGTT, and in the light of more recent epidemiological research seeks to place the current diagnostic criteria for diabetes into a pathophysiological, diagnostic and prognostic perspective. [Diabetologia (1997) 40: 247-255]

Keywords Diabetes mellitus, diagnosis, oral glucose tolerance test, fasting plasma glucose, 2-h plasma glucose, haemoglobin $\mathrm{A}_{1 \mathrm{c}}$, retinopathy, nephropathy, complications.
The current classification and diagnostic criteria for diabetes mellitus were introduced by the United States National Diabetes Data Group in 1979 [1] and with some modification endorsed by the World Health Organization (WHO) in 1980 [2] with further refinement in 1985 [3] and 1994 [4]. They were the synthesis of considerable thought and expertise and represented a consensus which, it was hoped, would prove helpful to all those involved with diabetes practising clinician, research scientist and epidemiologist alike. The diagnosis of diabetes, in the absence

Received: 7 August 1996 and in revised form: 19 November 1996

Corresponding author: Dr. D.R. McCance, Sir George E. Clark Metabolic Unit, Royal Victoria Hospital, Belfast, BT12, 6BA, Northern Ireland, UK

A bbreviations: WHO, World Health Organization; OGTT, oral glucose tolerance test; IDDM, insulin-dependent diabetes mellitus; NIDDM, non-insulin-dependent diabetes mellitus; IRI, immunoreactive insulin. of symptoms, depends on observing a high glucose concentration in blood obtained when the patient is fasting or during an oral glucose tolerance test (OGTT). Since insulin-dependent diabetes mellitus (IDDM) generally presents with symptoms or acute metabolic complications, these criteria, in practice, are usually applied to non-insulin-dependent diabetes mellitus (NIDDM) for which they were justified by the identification of persons at high risk of complications. By reviewing the original justification for the diagnostic criteria including the OGTT, and in the light of more recent epidemiological research, this article seeks to place the current diagnostic criteria for diabetes into pathophysiological, diagnostic and prognostic perspective. It is suggested that a reappraisal of the diagnostic criteria is now indicated.

\section{$\mathrm{H}$ istorical background}

The history of our understanding of diabetes provides an illuminating backdrop to the development of the 
current diagnostic criteria. This disease, recognised since antiquity [5], continues to excite, perplex and frustrate modern medicine and to impose a heavy financial burden.

Until the first quarter of the 20th century, classical symptoms and the presence of reducing substances in the urine were the hallmarks of diagnosis. With the advent of blood glucose measurement, fasting hyperglycaemia was the sine qua non of diagnosis [6]. The OGTT was introduced as a research tool in the $1920 \mathrm{~s}$ [7] and later was widely adopted as a diagnostic method $[8,9]$. In the intervening years many attempts have been made to refine both the test and the criteria for its interpretation. It was subsequently realised that the original diagnostic criteria for diabetes (the mean plus 2SD of glucose levels after an oral glucose load in healthy subjects) [9, 10], while defining a statistical abnormality, were not necessarily associated with any clinical abnormality at that time [11].

The question of which level of hyperglycaemia was diagnostic of diabetes became more than an intellectual curiosity when over the years following the discovery of insulin the full impact of the morbidity and mortality resulting from the microvascular complications and other less specific forms of vascular disease became clear. In the $1950 \mathrm{~s}$ and $1960 \mathrm{~s}$ emphasis on earlier recognition of the disease, with the hope that earlier treatment would prevent the development of complications, led to the widespread adoption of the OGTT to detect the condition at an early stage. The publication by West [12] of the widely differing blood glucose concentrations accepted as normal provided a stimulus to reach an international consensus.

\section{Dichotomising continuous variables}

Why are diagnostic criteria based on an artificial dichotomisation of a continuous variable? All diagnostic criteria for diabetes have been based on some mesurement of blood or urine glucose. Hyperglycaemia is the defining sign of diabetes, but the disease results from one or more of several underlying defects, such as islet cell autoimmunity or insulin resistance. These abnormalities, however, are not always accompanied by hyperglycaemia or symptoms or signs typical of diabetes. The diagnosis of diabetes should continue to be made by some measure of hyperglycaemia, but there will not be a perfect correlation between the underlying defects and any particular level of glycaemia. Thus, the choice of a diagnostic level is problematic, and can be based on many factors, including associations of various levels of hyperglycaemia with signs or symptoms and risk of long-term complications of diabetes.
M easures of hyperglycaemia as diagnostic criteria for diabetes

Two-hour post-load plasma glucose. Population frequency distributions of blood glucose provided an approach to diagnosing diabetes. In Pima Indians 2-h post-load glucose concentrations are bimodally distributed [13, 14] (Fig.1). Epidemiological surveys of other populations with a high prevalence of NIDDM including Mexican-Americans [15], Micronesians [16], Polynesians [17], and non-diabetic relatives of Caucasian subjects with NIDDM [18], have also demonstrated bimodality of 2-h post-load plasma glucose concentrations. In each of these populations the distribution was fitted better by a model of two overlapping normal distributions than by a single distribution. This suggested the presence of two subgroups differentiated by the degree of hyperglycaemia with the upper component of the frequency distribution representing diabetes. Longitudinal population studies indicated that at young ages most subjects were in the lower component of the distribution, but with advancing age some moved to the upper component, that is, developed diabetes.

Further support for equating diabetes with the upper component of the bimodal frequency distribution as defined by 2-h plasma glucose came from crosssectional and longitudinal observations in Pima Indians and in the Whitehall and Bedford studies in the United Kingdom which showed that both retinopathy and nephropathy occurred almost exclusively among subjects with plasma glucose levels in the upper component [19-22] (Fig.1). During a follow-up of 58 years, all three studies indicated that retinopathy developed almost exclusively in subjects with initial plasma glucose levels greater than $11.1 \mathrm{mmol} / \mathrm{l}$. As a result of these findings, criteria based on the OGTT were adopted by the National Diabetes Data Group [1] and the WHO [2-4] (Table 1). Implicit in the OGTT criteria was the inference that a diagnostic level of blood glucose indicated an increased risk for the development of microvascular complications [23].

The relationship between glucose-stimulated insulin concentrations and the 2-h plasma glucose concentration shows an inverted U-shape [24-31]. The point of inflection of the insulin-glucose curve corresponds approximately with the antimode of the frequency distribution of 2-h post-load plasma glucose concentrations and with a threshold for the prevalence of complications. This correspondence may provide the physiologic basis for the bimodality of glucose concentrations in that glucose concentrations are not stable at this level due to failing insulin secretion. This observation provides further support for a cut off point dividing the population into those with and without diabetes.

Fasting plasma glucose. The simplicity of fasting plasma glucose measurement has resulted in it being 

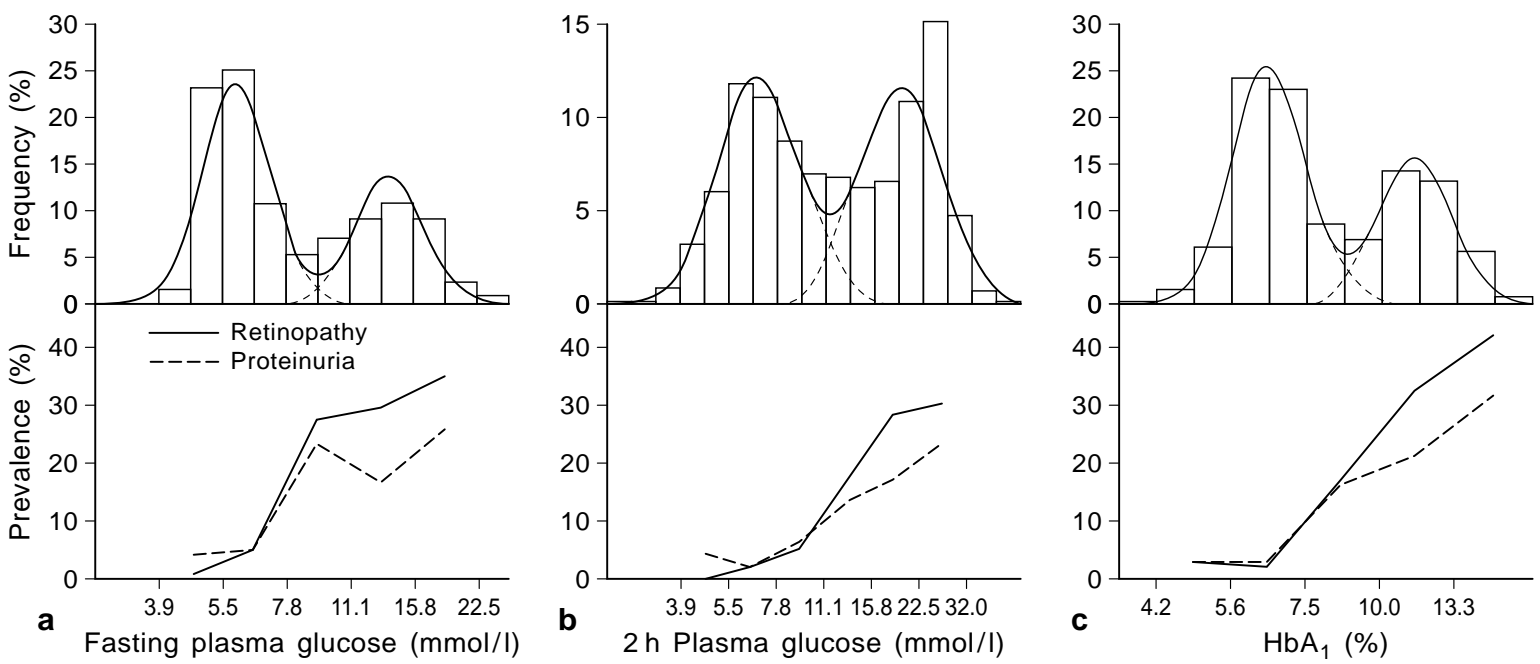

Fig. 1a-c. U pper panel: Frequency distributions of fasting plasma glucose (a), 2-h plasma glucose (b) and glycated haemoglobin (c) in subjects aged at least 35 years regardless of previously diagnosed diabetes or hypoglycaemic treatment. For each variable the bars show frequencies by intervals which are equally spaced on a logarithmic scale. The smooth curves represent a mathematical model of two overlapping normal distributions with a common variance which was fit by maximum likelihood. L ower panel: Prevalence of retinopathy and heavy proteinuria in the same subjects according to glucose concentrations or glycated haemoglobin [37]

Table 1. World Health Organization criteria for the OGTT

\begin{tabular}{llll}
\hline & \multicolumn{3}{l}{ Venous plasma glucose $(\mathrm{mmol} / \mathrm{l})$} \\
\cline { 2 - 4 } Category & Fasting & 2 -h \\
\hline Normal glucose tolerance & $<7.8$ & and & $<7.8$ \\
Impaired glucose tolerance & $<7.8$ & and & $7.8-11.0$ \\
Diabetes & $\geq 7.8$ & or & $\geq 11.1$ \\
\hline
\end{tabular}

While the terminology 'normal' is not used by WHO, it is used here to mean the absence of impaired glucose tolerance and diabetes. The two most widely used methods, venous plasma glucose (generally measured by a hospital laboratory on a venous specimen) and capillary whole blood glucose (measured by a self-monitoring enzyme-impregnated test strip), are equivalent at $2 \mathrm{~h}$ but not in the fasting state.

The criteria for impaired glucose tolerance defined by the NDDG [1] and the WHO [2,3] differ - the latter are used in this paper.

Cut-off points for serum glucose or capillary whole blood glucose are slightly different and can be found elsewhere [3]

subjected to epidemiological scrutiny similar to that of the 2 -h value $[16,19,20]$. It was soon realised that among the Pimas fasting glucose was also bimodally distributed and, as with 2-h glucose, there was a threshold for risk of complications (Fig. 1). On average, fasting insulin concentrations increase progressively with increasing glycaemia until the onset of NIDDM and then gradually decline. These latter two characteristics have been confirmed in longitudinal studies [30].
The above relationships were originally described with assays of total immunoreactive insulin (IRI), which do not distinguish insulin from proinsulin and other products of insulin secretion. A smaller proportion of IRI is true insulin at higher degrees of hyperglycaemia, yet the same pattern of a positive association of insulin with glucose over the glycaemic range was confirmed when the proinsulin concentration was subtracted from IRI [31].

The intravenous glucose tolerance test provides a supraphysiological short-term stimulus to insulin secretion and a 'first phase' insulin response can be precisely measured. That the acute insulin response is mostly absent when the fasting glucose level is greater than $6.4 \mathrm{mmol} / \mathrm{l}$ [32] supports an upper limit of normal fasting glucose similar to that proposed by the National Diabetes Data Group [1]. Reports on firstphase insulin secretion in impaired glucose tolerance are conflicting although in a recent study the first phase insulin response was absent in subjects with persistent impaired glucose tolerance [33].

Fasting plasma glucose concentrations considered consistent with a diagnosis of diabetes were defined by Fajans and Conn [9], by Mosenthal and Barry [10] and more recently by the WHO [2-4]. Although fasting plasma glucose may be used to diagnose diabetes (greater than $7.8 \mathrm{mmol} / \mathrm{l}$, WHO criteria), and is currently being used as a major entrance criterion (greater than $6.0 \mathrm{mmol} / \mathrm{l}$ ) in the United Kingdom Prospective Diabetes Study [34], its value as a diagnostic tool has largely been replaced by 2 -h plasma glucose when the OGTT is performed in epidemiological studies. This is perhaps a result of misconceptions that have arisen regarding the inter-relation of the fasting and 2-h glucose concentrations. There is often a failure to realise that, although these two measures are highly correlated, the 2-h and fasting values defined as diagnostic of diabetes by the WHO criteria are not equivalent. In a survey of the United States adult population, approximately three quarters of subjects without previously known diabetes but with 
diagnostic 2-h plasma glucose concentrations greater than $11.1 \mathrm{mmol} / \mathrm{l}$ had fasting glucose values below the level defined as diagnostic by the WHO ( $7.8 \mathrm{mmol} / \mathrm{l})$ [35]. On the other hand, nearly all persons with fasting plasma glucose greater than $7.8 \mathrm{mmol} / \mathrm{l}$ had 2-h glucose concentrations $11.1 \mathrm{mmol} / \mathrm{l}$ or more. These diagnostic cut off points imply that if WHO criteria are to be applied, and it is considered necessary to diagnose all persons with unknown diabetes, measurement of fasting plasma glucose is inadequate and the OGTT must be used in all persons whose fasting glucose concentrations fall below the diagnostic level. This would not be necessary, however, if a lower diagnostic cut off point was adopted for fasting plasma glucose, as will be discussed. This would allow diagnosis and screening by the much simplier and more economical fasting plasma glucose measurement.

Glycated haemoglobin. Glycated haemoglobin is now established as the preferred method of monitoring long-term glycaemic control. In Pima Indians, glycated haemoglobin has the same desirable properties as the fasting and 2-h post-load plasma glucose concentrations, namely bimodality and a threshold for association with microvascular disease, especially retinopathy [36, 37] (Fig. 1). Its utility as a diagnostic test has been examined in many studies but, unfortunately, with few exceptions, these have been with reference to the OGTT [38-43]. Thus, while most writers have concluded that glycated haemoglobin is an inadequate diagnostic test, this conclusion is based on the assumption that the OGTT represents the 'gold standard'.

\section{Comparison of measures of hyperglycaemia}

The specific complications of diabetes represent an alternative standard by which to compare diagnostic tests. Although the microvascular complications of diabetes cannot be equated with diabetes, they do represent a specific and relevant clinical endpoint by which to judge alternative tests. We have recently compared the three measures, plasma glucose, fasting and 2 hours after a $75 \mathrm{~g}$ load and glycated haemoglobin to diagnose diabetes in this perspective [44]. Cross-sectional and longitudinal studies were performed among 960 Pima Indian subjects aged 25 years and over who were not receiving insulin or oral hypoglycaemic treatment at the baseline examination. All three variables were associated with retinopathy with evidence of a threshold below which retinopathy was absent or rare and above which the prevalence and incidence of retinopathy were high (Fig. 2). All three measures of glycaemia were also associated with nephropathy but not as strongly as with retinopathy. The 2-h plasma glucose was superior to

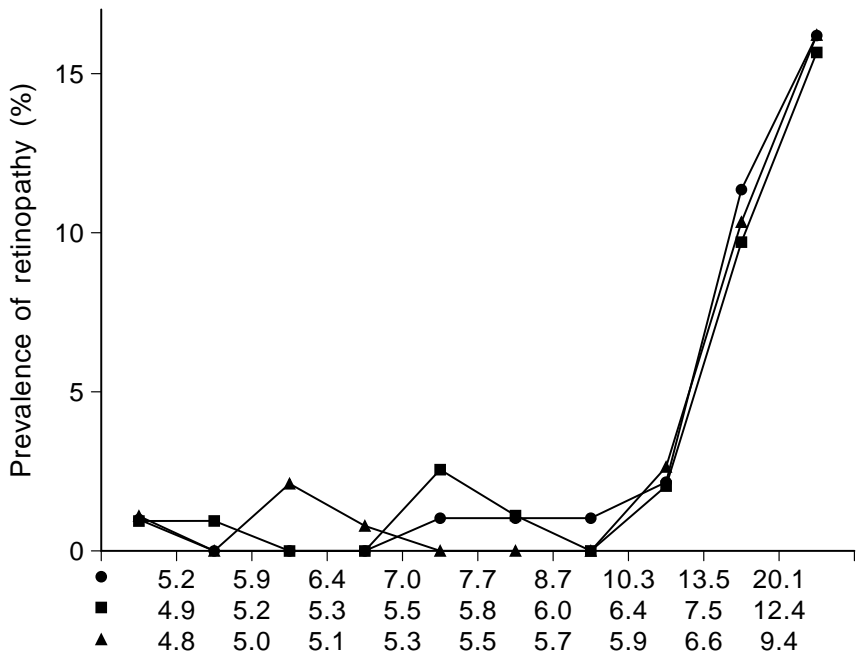

Fig. 2. Prevalence of retinopathy in relation to tenths of 2-h plasma glucose, fasting plasma glucose, and haemoglobin $\mathrm{A}_{1 \mathrm{c}}$ [44]

fasting glucose for predicting the presence of retinopathy but otherwise no variable was significantly more strongly associated with prevalent or incident cases of either complication [44]. In another study of Pima Indians previously diagnosed by WHO criteria, the three measures of glycaemia were also found to be equivalent as predictors of retinopathy [45].

The relationships of fasting and 2 -h plasma glucose and glycated haemoglobin with macrovascular complications were examined in Islington, UK [46] and in Hoorn, the Netherlands [47]. In both studies all three measures had similar associations with peripheral vascular disease [46, 47]. In Islington however, the 2-h glucose was most strongly associated with major coronary heart disease [46]. In the Paris Prospective Study, the incidence of fatal cardiovascular disease was related to the fasting and 2-h plasma glucose concentrations at a baseline examination. There was a marked increase in incidence of disease at a fasting plasma glucose greater than $6.9 \mathrm{mmol} / \mathrm{l}$, similar to the increased incidence at 2-h plasma glucose greater than $11.1 \mathrm{mmol} / \mathrm{l}$ [47a]. Data from the Pima Indians and those cited above which have pointed to the equivalence of fasting and 2-h plasma glucose require confirmation in other populations and for various complications.

An alternative approach to the selection of diagnostic criteria is to determine a threshold that best separates those at high and low risk of specific complications for diabetes. In fact, the risk for retinopathy, as demonstrated in epidemiological studies, was an implicit rationale behind the derivation of the 2-h $11.1 \mathrm{mmol} / \mathrm{l}$ criterion. In Pima Indians, values of fasting glucose and glycated haemoglobin equivalent to the $11.1 \mathrm{mmol} / \mathrm{l}$ WHO 2-h criterion have been derived from those points with similar ratios of sensitivity to specificity for retinopathy; points which give the 
Table 2. Cut-off points based on three different methods

\begin{tabular}{lcll}
\hline & $\begin{array}{l}\text { 2-h plasma } \\
\text { glucose } \\
(\mathrm{mmol} / \mathrm{l})\end{array}$ & $\begin{array}{l}\text { Fasting plasma } \\
\text { glucose } \\
\text { (mmol/l) }\end{array}$ & $\begin{array}{l}\mathrm{HbA}_{1 \mathrm{c}} \\
(\%)\end{array}$ \\
\hline Antimodal $^{\mathrm{a}}$ & 12.6 & 9.3 & 7.8 \\
$\begin{array}{l}\text { Equivalent to WHO }^{\mathrm{b}} \\
\begin{array}{l}\text { Equivalent to WHO } \\
\text { prevalence }^{\mathrm{d}}\end{array}\end{array}$ & $(11.1)^{\mathrm{c}}$ & 6.8 & 6.1 \\
\hline
\end{tabular}

a Antimode of the frequency distribution fit by two overlapping normal curves [44]

${ }^{b}$ Defined as the point with the same ratio of sensitivity to 1-specificity for retinopathy as the WHO 2-h criterion of $11.1 \mathrm{mmol} / \mathrm{l}[44]$

c $11.1 \mathrm{mmol} / \mathrm{l}$ by definition

${ }^{\mathrm{d}}$ Defined as the point which gives the same prevalence of diabetes as the WHO 2-h criterion of $11.1 \mathrm{mmol} / \mathrm{l}$ [48]

same prevalence of diabetes as the WHO 2-h criterion can also be obtained [48] and these points are nearly identical to these defined by the relationship with retinopathy (Table 2 ). Other possibilities include the point of maximum separation of frequency distributions of these values or that which maximises the sum of sensitivity and specificity for retinopathy [44]. Ultimately, the costs and benefits of a diagnosis and its consequences should be considered in choosing a diagnostic cut off point.

All three tests have disadvantages in some situations. The OGTT is subject to considerable intra-individual variation $[18,49-51]$ and fasting plasma glucose appears preferable to 2-h plasma glucose in this respect. In a recent study of Dutch adults, in which the OGTT was repeated during a 2-6-week interval, the intra-individual coefficients of variation were $6.4 \%$ for fasting glucose and $16.7 \%$ for the 2 -h plasma glucose [51]. Glycated haemoglobin has proven difficult to standardize [52] and is not as widely available as a measurement of glucose concentrations. Published studies which have compared the utility of this test with fasting and 2-h plasma glucose used different assays, thus making it difficult to assign an appropriate cut off point. These problems with glycated haemoglobin need to be solved before any criteria based on this measure can be universally applied. The fasting plasma glucose is probably the best single test for diagnosing diabetes because of its simplicity, low cost, reproducibility and worldwide availability.

\section{D iagnosis of diabetes in pregnancy}

Diagnostic criteria for diabetes have evolved somewhat differently in pregnant and non-pregnant adults. This has resulted in much confusion and a lack of comparability between studies [53-63] and even between different tests in the same person, if, as recommended by the National Diabetes Data Group and practised in the United States, different test procedures are used during and after pregnancy. Several diagnostic methods, with their attendant cut off points, have been used, including the two-step OGTT procedure of O'Sullivan and Mahan [64] (endorsed by the United States National Diabetes Data Group, and, with modified cut off points by Carpenter and Coustan [65]), the single 75-g OGTT interpreted by a variety of criteria (e.g. WHO [1, 2], Diabetic Pregnancy Study Group of the European Association for the Study of Diabetes [DPSG-EASD] [56]), and standardized meal tolerance tests [66, 67]. Data obtained using each of these methods has been associated with maternal-fetal outcome [64, 68-71], and in some cases, to long-term outcome in the child [7275]. The differences between cut off points used in different schemes (e.g. WHO and DPSG-EASD) reflect the inherent arbitrariness of cut off points for classifications based on continuously distributed data in the absence of evidence for a threshold predicting adverse outcomes in the mother or child.

With few exceptions, these testing methods have not been compared with each other, so it is impossible to determine if any one of them is superior to another in predicting adverse maternal or fetal outcomes. In one small study in Pima Indians [76] that compared the WHO and O'Sullivan and Mahan criteria (adapted to a 75-g load screen) in the same women, the O'Sullivan procedure was much less sensitive than the WHO procedure in predicting adverse maternal or fetal outcome. A more recent larger study reached similar conclusions demonstrating that the WHO criteria detected abnormalities in a greater proportion of women with adverse outcomes than the NDDG criteria [77].

The essential question for the future is whether these tests differ in predicting pregnancy outcome both in terms of the immediate consequences on the maternal-fetal unit and the future health of mother and child. The 75-g OGTT performed and interpreted by WHO criteria offers comparability with the non-pregnant state, which is another argument for its universal adoption for the diagnosis of diabetes in pregnancy.

\section{D iagnosing the undiagnosed}

In the United States about half the people with diabetes according to WHO criteria are undiagnosed [35, 78]. This finding raises the obvious question of whether these undiagnosed diabetic persons should be detected and treated. This question is related to several key issues in screening for disease: 1) availability, accuracy, and acceptability of a screening test, 2) organizational and medical resources necessary for screening, referral and treatment, and 3) benefits and adverse effects of making a diagnosis. The 
potential benefits of early diagnosis and treatment of diabetes might include a low incidence of symptoms or the acute or chronic complications of disease. Possible adverse effects include the psychological and economic damage caused by diagnosis and treatment which may be without medical benefit. These issues have been thoroughly discussed in relation to diabetes [79-83]. In many parts of the world, tests and resources for screening are readily available, but the question of benefits and costs of making a new diagnosis are difficult to answer. Screening procedures are clearly indicated for pregnant women and people with symptoms and signs suspected of being caused by diabetes and for those with diseases often associated with diabetes, for whom diagosis and treatment of diabetes would help in their management. Other than in pilot studies [84, 85], widespread screening for diabetes outside the context of regular medical care has not been instituted, and probably will not be, until better evidence of benefit is forthcoming. Screening could be carried out not only for diabetes, but also for lesser degrees of hyperglycaemia, such as impaired glucose tolerance, if clinical trials currently in progress demonstrate a benefit in treating this condition. In the future, screening for diabetessusceptibility alleles [86-88] at specific genetic loci may further identify those individuals at increased risk of diabetes, but again, benefit of detecting persons with such genetic susceptibility should be demonstrated before such screening is widely advocated. Screening would become much easier to implement if the fasting plasma glucose became the standard diagnostic test and thus easy to apply on a large scale. This would eliminate the need for separate screening and diagnostic tests [79].

\section{Unresolved issues}

Data on bimodality and association with complications in Pima Indians and other populations [46, 47, 47 a] suggest that the OGTT may not be necessary, as the same quality of information can be obtained by measurement of fasting plasma glucose or glycated haemoglobin. These findings need to be replicated or refuted in a wide variety of populations. The glycaemic thresholds for specific complications of diabetes and for other adverse health events are not yet precisely defined. Furthermore, measurements of serum insulin concentrations during the OGTT have been useful in pathophysiologic studies [29, 30, 89, 90]. Thus, while the currently available data suggest that the OGTT is not necessary for clinical purposes, it still may have a role in research. The optimal cut off point for diagnosis based on any of the quantitative variables cannot be determined solely from the types of data reviewed in this paper. Costs are considered in evaluating screening strategies, but they are also critical in choosing a diagnostic level for diabetes. This is because the diagnosis of diabetes is not based on the presence of a discrete physiological abnormality, but by an imperfectly chosen point on a continuum of glycaemia. The choice of the cut off point depends on the medical, psychological, social and economic costs of making a diagnosis in someone who is not at substantial risk of diabetes-related symptoms or complications, or of not making a diagnosis in someone who is. The choice of exact cut off points should be made with consideration of costs, for which adequate data are, unfortunately, not available. Any dichotomous cut off point, however, will inevitably mask information regarding the severity of disease. The selection of glucose cut off points for making decisions about therapy is an additional question beyond that of diagnosing diabetes; therapeutic cut off points are not necessarily the same as diagnostic cut off points.

Each of the three tests of hyperglycaemia has disadvantages in some situations. The OGTT is subject to considerable intra-individual variation and glycated haemoglobin has proved difficult to standardise. None of these tests will be useful if it cannot be performed reliably. The choice of a diagnostic test may well be determined by local circumstances.

\section{Conclusions}

This review has discussed the definition of diabetes from pathophysiological, diagnostic and prognostic perspectives. In the last 10 years we have witnessed change both of horizon and perspective which has altered our conception and appreciation of the diagnosis of diabetes. The OGTT has remained the gold standard for over 60 years despite its biological and methodological limitations. A more fundamental or causal classification for the most common types of diabetes will undoubtedly be helpful. Nonetheless, glucose will presumably always be a major toxic factor whatever the aetiologic determinant; therefore hyperglycaemia is likely to remain the basis of the diagnosis of diabetes mellitus.

Are new diagnostic criteria needed? Epidemiologic data suggest that fasting and 2-h plasma glucose and glycated haemoglobin are equivalent for diagnostic purposes and this equivalence should be acknowledged in diagnostic criteria for diabetes. While the choice of cut off points depends on many considerations, those equivalent to the $11.1 \mathrm{mmol}$ WHO criterion in terms of their relationship with retinopathy (e.g. fasting venous plasma glucose $\sim 7 \mathrm{mmol} / \mathrm{l}$ ) offer continuity with the past and compatibility with current clinical and epidemiological research. This diagnostic level was proposed by a Workgroup of the American Diabetes Association [91]. 


\section{References}

1. National Diabetes Data Group (1979) Classification and diagnosis of diabetes mellitus and other categories of glucose intolerance. Diabetes 28: 1039-1057

2. World Health Organization Expert Committee on Diabetes Mellitus (1980) Second Report. Technical report series 646. WHO, Geneva

3. World Health Organization Study Group on Diabetes Mellitus (1985) Technical report series 727. WHO, Geneva

4. Prevention of diabetes mellitus (1994) Report of WHO Study Group. Technical Report Series 844. WHO, Geneva

5. Marble A (1971) Correct concepts of diabetes. In: A. Marble, P. White, RF Bradley, LP Krall (eds) Joslin's Diabetes Mellitus. 11th edn. Lea and Febiger, Philadelphia pp 1-9

6. Bennett PH (1983) The diagnosis of diabetes. New international classification and diagnostic criteria. Ann Rev Med 34: 295-309

7. John HJ (1922) Glucose tolerance and its value in diagnosis. Journal of Metabolic Research 1: 497-548

8. Mayer JH, Womack CR (1950) Glucose tolerance 1. A comparison of four types of diagnostic tests in 103 subjects and 26 patients with diabetes. Am J Med Sci 219: 161-173

9. Fajans SS, Conn JW (1959) The early recognition of diabetes mellitus. Ann NY Acad Sci 82: 208-218

10. Mosenthal HO, Barry E (1950) Criteria for an interpretation of normal glucose tolerance tests. Ann Intern Med 33: 1175-1194

11. Siperstein MD (1975) The glucose tolerance test: a pitfall in the diagnosis of diabetes mellitus. Adv Intern Med 20: $297-$ 323

12. West KM (1975) Substantial differences in the diagnostic criteria used by diabetes experts. Diabetes 24: 641-644

13. Rushforth NB, Bennett PH, Burch et al. (1971) Diabetes in the Pima Indians, evidence of bimodality in glucose tolerance distributions. Diabetes 20: 756-765

14. Rushforth NB, Bennett PH, Steinberg AG, Miller M (1975) Comparison of the two- and one-hour glucose levels of the oral GTT in the diagnosis of diabetes in Pima Indians. Diabetes 24: 538-546

15. Rosenthal M, McMahan CA, Stern MP (1985) Evidence of bimodality of two-hour plasma glucose concentrations in Mexican-Americans: results from the San Antonio heart study. J Chron Dis 38: 5-16

16. Zimmet P, Whitehouse S (1978) Bimodality of fasting and two-hour glucose tolerance distributed in a Micronesian population. Diabetes 27: 793-800

17. Raper LR, Taylor R. Zimmet P et al. (1984) Bimodality in glucose tolerance distributions in the urban Polynesian population of Western Samoa. Diabetes Res 1: 19-26

18. Tillil H, Richter, Kobberling J (1985) Bimodal distribution of the 2-hour blood glucose value during OGTT among first-degree relatives of type 2-diabetics in a Caucasoid population. Diabetes Res Clin Pract [Suppl 1]; S650

19. Rushforth NB, Miller M, Bennett PH (1979) Fasting and two-hour post-load glucose levels for the diagnosis of diabetes. The relationship between glucose levels and complications of diabetes in the Pima Indians. Diabetologia 16: 373-379

20. Pettitt DJ, Knowler WC, Lisse JR, Bennett PH (1980) Development of retinopathy and proteinuria in relation to plasma glucose concentrations in Pima Indians. Lancet ii:1050-1052

21. Sayegh HAI, Jarrett RJ (1979) Oral glucose tolerance tests and the diagnosis of diabetes: results of a prospective study based on the Whitehall Study. Lancet 1: 431-433
22. Jarrett RJ, Keen H (1976) Hyperglycaemia and diabetes mellitus. Lancet 1: 1009-1011

23. Bennett PH, Knowler WC, Pettitt DJ, Lisse JR (1980) The prognostic significance of the glucose tolerance test. In: Cumming IA, Funder JW, Mendelsohn FAO (eds) Proceedings VI International Congress of Endocrinology. Elsevier/ North Holland, Bimedical Press, Amsterdam pp 711-714

24. Reaven G, Miller R (1968) Study of the relationship between glucose and insulin responses to an oral glucose load in man. Diabetes 17: 560-569

25. Welborn TA, Stenhouse NS, Johnstone CG (1969) Factors determining serum insulin response in a population sample. Diabetologia 5: 263-266

26. Savage PJ, Dippe SE, Bennett PH et al. (1975) Hyperinsulinaemia and hypoinsulinaemia. Insulin responses to oral carbohydrate over a wide spectrum of glucose tolerance. Diabetes 24: 362-368

27. Zimmet P, Whitehouse S, Alford F, Chisholm D (1978) The relationship of insulin to a glucose stimulus over a wide range of glucose tolerance. Diabetologia 15: 23-27

28. Lillioja S, Mott DM, Howard BV et al. (1988) Impaired glucose tolerance as a disorder of insulin action: longitudinal and cross-sectional studies in Pima Indians. New Engl J Med 318: 1217-1225

29. Sicree RA, Zimmet P, King OM, Coventry JS (1987) Plasma insulin response among Nauruans: prediction of deterioration in glucose tolerance over 6 years. Diabetes 36: 179186

30. Saad MF, Knowler WC, Pettitt DJ, Nelson RG, Mott DM, Bennett PH (1989) Sequential changes in serum insulin concentration during development of non-insulin-dependent diabetes. Lancet i:1356-1359

31. Saad MF, Kahn SE, Nelson RG et al. (1990) Disproportionately elevated proinsulin in Pima Indians with noninsulin-dependent diabetes mellitus. J Clin Endocrinol Metab 70: $1247-1253$

32. Brunzell JD, Robertson RP, Lerner RL et al. (1976) Relationships between fasting plasma glucose levels and insulin secretion during intravenous glucose tolerance tests. J Clin Endocrinol Metab 42: 222

33. Davies MJ, Rayman G, Grenfell A, Gray IP, Day J, Hales CN (1994) Loss of first phase insulin response to intravenous glucose in subjects with persistent impaired glucose tolerance. Diabet Med 11: 432-436

34. UK Prospective Diabetes Study (UKPDS) (1991) Study design, progress and performance. Diabetologia 34: 877890

35. Harris MI, Hadden WC, Knowler WC, Bennett PH (1987) Prevalence of diabetes and impaired glucose tolerance and plasma glucose levels in US population aged 20-74 yr. Diabetes 36: 523-534

36. Flock EV, Bennett PH, Savage PJ et al. (1979) Bimodality of glycosylated haemoglobin distribution in Pima Indians; relationship to fasting hyperglycaemia. Diabetes 28: 984989

37. Knowler WC, Pettitt DJ, Saad MF, Bennett PH (1990) Diabetes mellitus in the Pima Indians: incidence, risk factors and pathogenesis. Diabetes Metab Rev 6: 1-27

38. Santiago JV, Davis JE, Fisner F (1978) Haemoglobin $\mathrm{A}_{1 \mathrm{c}}$ levels in a diabetes detection program. J Clin Endocrinol Metab 47: 578-580

39. Lester E, Frazer AD, Shepherd CA, Woodroffe FJ (1985) Glycosylated haemoglobin as an alternative to the glucose tolerance test for the diagnosis of diabetes mellitus. Ann Clin Biochem 22: 74-78

40. Forrest RD, Jackson CA, Gould BJ, Casbum-Budd M, Taylor JE, Yudkin JS (1988) Four assay methods for glycated 
haemoglobin compared as screening tests for diabetes mellitus: the Islington diabetes survey. Clin Chem 34: 145-148

41. Little RR, England JD, Wiedmeyer HM et al. (1988) Relationship of glycosylated haemoglobin to oral glucose tolerance. Diabetes 37: 60-64

42. Forrest RD, Jackson CA, Yudkin JS (1987) The glycohaemoglobin assay as a screening test for diabetes mellitus: the Islington diabetes survey. Diabet Med 4:254-259

43. Hanson RL, Nelson RG, McCance DR et al. (1993) Comparison of screening tests for non-insulin-dependent diabetes mellitus. Arch Intern Med 153: 2133-2140

44. McCance DR, Hanson RL, Charles MA et al. (1994) Comparison of tests for glycated haemoglobin and fasting and two hour plasma glucose concentrations as diagnostic methods for diabetes. BMJ 308: 1323-1328

45. Liu QZ, Pettitt DJ, Hanson RL et al. (1993) Glycated haemoglobin, plasma glucose and diabetic retinopathy: crosssectional and prospective analyses. Diabetologia 36: 428432

46. Jackson CA, Yudkin JS, Forrest RD (1992) A comparison of the relationships of the glucose tolerance test and the glycosylated haemoglobin assay with diabetic vascular disease in the community. The Islington Diabetes Survey. Diabetes Res Clin Pract 17: 111-123

47. Beks PH, Mackaay AJC, de Neeling JND, de Vries, Bouter LM, Heine RJ (1995) Peripheral arterial disease in relation to glycaemic level in an elderly Caucasian population: the Hoorn Study. Diabetologia 38: 86-96

47 a. Charles MA, Balkau B, Vauzelle-Kervröedan F, Thibult $\mathrm{N}$, Eschwège E (1996) Revision of diagnostic criteria for diabetes. Lancet 348: 1657-1658

48. Finch CF, Zimmett PZ, Alberti KGMM (1990) Determining diabetes prevalence: a rational basis for the use of fasting plasma glucose concentrations? Diabetic Med 7: 603610

49. McDonald GWM, Fisher GF, Burnham C (1965) Reproducibility of the oral glucose tolerance test. Diabetes 14 : 473-480

50. Olefsky JM, Reaven GM (1974) Insulin and glucose responses to identical oral glucose tolerance tests performed forty-eight hours apart. Diabetes 23: 449-453

51. Mooy JM, Gootenhuis PA, de Vries H et al. (1996) Intraindividual variation of glucose, specific insulin and proinsulin concentrations measured by two oral glucose tolerance tests in a general Caucasian population: the Hoorn Study. Diabetologia 39: 298-305

52. Kilpatrick ES, Rumley AG, Dominiczak MH, Small M (1994) Glycated haemoglobin values: problems in assessing blood glucose control in diabetes mellitus. BMJ 309: 983986

53. American Diabetes Association (1980) International Workshop- Conference on Gestational Diabetes, Chicago, Diabetes Care 3: 399-501

54. Proceedings of the Second International Workshop Conference on Gestational Diabetes Mellitus (1985) Diabetes 34 [Suppl 2]:1-126

55. Proceedings of the Third International Workshop on Gestational Diabetes Mellitus (1991) Diabetes 40 [Suppl 2]:1201

56. Diabetes Pregnancy Study Group (1989) A prospective multicentre study to determine the influence of pregnancy upon the 75-g oral glucose tolerance test (OGTT). In: Sutherland HN, Stowers JM, Pearson DWM (eds) Carbohydrate metabolism in pregnancy and the newborn IV. Springer-Verlag, London pp 209-226

57. Hunter DJS, Kierse MJNC (1989) Gestational diabetes. In: Chalmers I, Enkin M, Keirse MJNC (eds) Effective care in pregnancy and childbirth, vol 1. Oxford University Press, Oxford, pp 403-410

58. Naylor CD (1989) Diagnosing gestational diabetes mellitus. Is the gold standard valid? Diabetes Care 12: 565-572

59. Ales KL, Santini DL (1989) Should all pregnant women be screened for gestational glucose intolerance? Lancet i:1187-1191

60. Sacks DA, Abu-Fadil S, Greenspoon JS, Fotheringham N (1989) Do the current standards for glucose tolerance testing in pregnancy represent a valid conversion of O'Sullivan's original criteria? Am J Obstet Gynecol 161: 638-641

61. Hunter A, Doery JC, Miranda V (1990) Diagnosis of gestational diabetes in Australia: a national survey of current practice. Med J Aust 153: 290-292

62. American Diabetes Association Inc (1991) Position statement on gestational diabetes mellitus. Diabetes Care 14: 5-6

63. Jarrett RJ (1993) Gestational diabetes: a non-entity? BMJ 306: 37-38

64. O'Sullivan JB, Mahan CM (1964) Criteria for the oral glucose tolerance test in pregnancy. Diabetes 13: 278-285

65. Carpenter MW, Coustan DR (1982) Criteria for screening tests for gestational diabetes mellitus. Am J Obstet Gynecol 159: 768-773

66. Hadden DR (1989) Pregnancy problems in diabetics. In: Lawson DH (ed) Current Medicine 2, Churchill Livingstone, Edinburgh, pp 87-104

67. Sutherland HW, Pearson DWM, Lean MEJ, Campbell DM (1989) Breakfast tolerance test in pregnancy. In: Sutherland HW, Stowers JM, Pearson DWM (eds) Carbohydrate metabolism in pregnancy and the newborn IV. Springer Verlag, London, pp 267-275

68. O'Sullivan JB, Charles D, Mahan CM, Dandrow RV (1973) Gestational diabetes and perinatal mortality rate. Am J Obstet Gynecol 116: 901-904

69. Roversi GD, Gargiulo M, Nicolini U (1980) Maximal tolerated insulin therapy in gestational diabetes mellitus. Diabetes Care 3: 489-494

70. Pettitt DJ, Knowler WC, Baird HR, Bennett PH (1980) Gestational diabetes: infant and maternal complications of pregnancy in relation to third-trimester glucose tolerance in Pima Indians. Diabetes Care 3: 458-464

71. Abell DA, Beischer NA (1975) Evaluation of three-hour oral glucose tolerance test in detection of significant hyperglycaemia and hypoglycaemia in pregnancy. Diabetes 24 : 874-880

72. Pettitt DJ, Baird HR, Aleck KA, Bennett PH, Knowler WC (1983) Excessive obesity in offspring of Pima Indian women with diabetes during pregnancy. New Engl J Med 308: 242-245

73. Pettitt DJ, Aleck KA, Baird HR, Carraher MJ, Bennett PH, Knowler WC (1988) Congenital susceptibility to NIDDM: the role of the intrauterine environment. Diabetes 37: 622-628

74. Martin A, Simpson J, Ober C, Freinkel N (1985) Frequency of diabetes mellitus in mothers of probands with gestational diabetes: possible maternal influence on the predisposition to gestational diabetes. Am J Obstet Gynecol 151: 471-475

75. Alcolado JC, Alcolado R (1991) Importance of maternal history of non-insulin-dependent diabetic patients. BMJ 302: 1178-1180

76. Pettitt DJ, Bennett PH, Hanson RL, Narayan KMV, Knowler WC (1995) Comparison of World Health Organization and National Diabetes Data Group procedures to detect abnormalities of glucose tolerance during pregnancy. Diabetes Care 9: 1264-1268 
77. Deerochanawong C, Putiyanun C, Wongsuryrat M, Serirat S, Jinayon P (1996) Comparison of National Diabetes Data Group and World Health Organization criteria for detecting gestational diabetes mellitus. Diabetologia 39: 1070-1073

78. Harris MI (1993) Kelly West Lecture: Undiagnosed NIDDM, clinical and public health issues. Diabetes Care 16: 642-652

79. Knowler WC (1994) Screening for NIDDM. Opportunities for detection, treatment and prevention. Diabetes Care 17: $445-450$

80. Newman WP, Nelson R, Scheer K (1994) Community screening for Diabetes. Low detection rate in low risk population. Diabetes Care 17: 363-365

81. Home P (1994) Diagnosing the undiagnosed with diabetes. BMJ 308: 611-612

82. Singh BM, Jackson DMA, Davies J, Wills R, Wise PH (1992) Delayed diagnosis in non-insulin-dependent diabetes mellitus. BMJ 304: 1154-1155

83. Harris MI, Modan M (1994) Screening for NIDDM: why is there no national programme? Diabetes Care 17: 440-444

84. Singh BM, Prescott JJW, Guy R, Walford S, Murphy M, Wise PH (1994) Effect of advertising on awareness of symptoms of diabetes among the general public: the British Diabetic Association study. BMJ 308: 632-636
85. Davies M, Alban-Davies H, Cook C, Day J (1991) Self testing for diabetes mellitus. BMJ 303: 696-698

86. Vionnet N, Stoffel M, Takeda J et al. (1992) Nonsense mutation in the glucokinase gene causes early-onset non-insulin-dependent diabetes mellitus. Nature 356: 721-722

87. Hattersley AT, Turner RC, Permutt MA et al. (1992) Linkage of type 2 diabetes to the glucokinase gene. Lancet 339: $1307-1310$

88. Bell GI, Xiang KS, Newman MV et al. (1991) Gene for non-insulin-dependent diabetes mellitus (maturity-onset diabetes of the youth subtype) is linked to DNA polymorphism on human chromosome 20q. Proc Natl Acad Sci USA 88: 1484-14881

89. Saad MF, Knowler WC, Pettitt DJ, Nelson RG, Charles MA, Bennett PH (1991) A two-step model for development of non-insulin-dependent diabetes. Am J Med 90: 229-235

90. Hofman A, Grobbee DE, de Jong PTVM, van der Ouweland FA (1991) Determinants of disease in the elderly: the Rotterdam Elderly Study. Eur J Epidemiol 7: 403-422

91. Gavin JR on behalf of the American Diabetes Association (ADA) Workgroup on Screening, Classification and Diagnosis of Diabetes Mellitus. Presented at the ADA Annual Meeting, San Francisco, June 1996 